\title{
LRAD3, A Novel Low-Density Lipoprotein Receptor Family Member That Modulates Amyloid Precursor Protein Trafficking
}

\author{
Sripriya Ranganathan, ${ }^{1}$ Nathaniel C. Noyes, ${ }^{1}$ Mary Migliorini, ${ }^{1}$ Jeffrey A. Winkles, ${ }^{1}$ Frances D. Battey, ${ }^{1}$ \\ Bradley T. Hyman, ${ }^{2}$ Elizabeth Smith, ${ }^{1}$ Manuel Yepes, ${ }^{3}$ Irina Mikhailenko, ${ }^{1}$ and Dudley K. Strickland ${ }^{1}$ \\ ${ }^{1}$ Center for Vascular and Inflammatory Diseases and the Departments of Surgery and Physiology, University of Maryland School of Medicine, Baltimore, \\ Maryland 21201, ${ }^{2}$ Alzheimer's Disease Research Laboratory, Department of Neurology, Massachusetts General Institute for Neurodegenerative Disease, \\ Massachusetts General Hospital, Harvard Medical School, Charlestown, Massachusetts 02129, and the ${ }^{3}$ Department of Neurology and Center for \\ Neurodegenerative Disease, Emory University School of Medicine, Atlanta, Georgia 30322
}

We have identified a novel low-density lipoprotein (LDL) receptor family member, termed LDL receptor class A domain containing 3 (LRAD3), which is expressed in neurons. The LRAD3 gene encodes an $\sim 50 \mathrm{kDa}$ type I transmembrane receptor with an ectodomain containing three LDLa repeats, a transmembrane domain, and a cytoplasmic domain containing a conserved dileucine internalization motif and two polyproline motifs with potential to interact with WW-domain-containing proteins. Immunohistochemical analysis of mouse brain reveals LRAD3 expression in the cortex and hippocampus. In the mouse hippocampal-derived cell line HT22, LRAD3 partially colocalizes with amyloid precursor protein (APP) and interacts with APP as revealed by coimmunoprecipitation experiments. To identify the portion of APP that interacts with LRAD3, we used solid-phase binding assays that demonstrated that LRAD3 failed to bind to a soluble APP fragment $(\operatorname{sAPP} \alpha)$ released after $\alpha$-secretase cleavage. In contrast, $\mathrm{C} 99$, the $\beta$-secretase product that remains cell associated, coprecipitated with LRAD3, confirming that regions within this portion of APP are important for associating with LRAD3. The association of LRAD3 with APP increases the amyloidogenic pathway of APP processing, resulting in a decrease in sAPP $\alpha$ production and increased $\mathrm{A} \beta$ peptide production. Pulse-chase experiments confirm that LRAD3 expression significantly decreases the cellular half-life of mature APP. These results reveal that LRAD3 influences APP processing and raises the possibility that LRAD3 alters APP function in neurons, including its downstream signaling.

\section{Introduction}

The low-density lipoprotein (LDL) receptor family contains seven structurally related family members that include the LDL receptor (LDLR), the very-low-density lipoprotein receptor, apolipoprotein $\mathrm{E}$ (apoE) receptor 2, multiple epidermal growth factor-like domains 7, glycoprotein 330 (gp330/megalin/LRP2), the LDL receptor-related protein (LRP) 1, and LRP1B (Willnow et al., 1999; Herz and Strickland, 2001). This receptor family also includes additional members that are more distantly related, such as LRP5, LRP6, and SorLa/LRP11. The prototypic member of this receptor family is the LDL receptor, which has a cytoplasmic domain containing an NPXY internalization sequence, a transmembrane domain, an O-linked sugar domain, epidermal growth factor-like

Received Sept. 28, 2010; revised May 17, 2011; accepted May 19, 2011.

Author contributions: S.R. and D.K.S. designed research; S.R., N.C.N., M.M., J.A.W., F.D.B., E.S., M.Y., and I.M. performed research; J.A.W. contributed unpublished reagents/analytic tools; N.C.N., M.M., F.D.B., B.T.H., M.Y., I.M., and D.K.S. analyzed data; D.K.S. wrote the paper.

This work is supported by NIH Grants P01 HL54710 (D.K.S.), HL50784 (D.K.S.), NS55126 (J.A.W.), and NS49478 (M.Y.) and a Scientist Development Award from the American Heart Association (S.R.).

Correspondence should be addressed to Dudley K. Strickland, Center for Vascular and Inflammatory Diseases, University of Maryland School of Medicine, 800 West Baltimore Street, Room 219, Baltimore, MD 21201. dstrickland@som.umaryland.edu.

DOI:10.1523/JNEUROSCI.5065-10.2011

Copyright $\odot 2011$ the authors $\quad 0270-6474 / 11 / 3110836-11 \$ 15.00 / 0$ repeats, a $\beta$-propeller domain, and a cluster of cysteine-rich LDL receptor type A (LDLa) repeats that are responsible for binding the ligands (Yamamoto et al., 1984).

Several LDLR family members are expressed in the brain where they contribute to important physiological processes. One of the abundant neuronal receptors is LRP1, which has been found to regulate cholesterol homeostasis in neurons (Liu et al., 2007) and to regulate the integrity of the blood-brain barrier (Yepes et al., 2003). LRP1 was discovered to bind to the amyloid precursor protein (APP) (Kounnas et al., 1995; Knauer et al., 1996; Kinoshita et al., 2001), a transmembrane protein that is proteolytically processed to generate the $\beta$-amyloid (A $\beta$ ) peptide that is a major component of plaques in Alzheimer's patients. The association of LRP with APP alters its cellular trafficking, resulting in an increase in the production of the $\mathrm{A} \beta$ peptide (Ulery et al., 2000; Pietrzik et al., 2002, 2004), and thus LRP1 has been implicated in the pathology of Alzheimer's disease. Since the original discovery of the $\mathrm{A} \beta$ peptide and establishment of the hypothesis that this peptide induces the development of Alzheimer's disease (Hardy and Selkoe, 2002), studies have focused on mechanisms associated with modulating APP processing with a goal of influencing $A \beta$ production and possibly impacting the progression of Alzheimer's disease. 
To investigate whether additional LDLR family members exist that have the potential to impact APP processing, we screened the human EST database for novel LDLR-related genes expressed in the brain and identified an uncharacterized LDLR family member that is expressed in microvascular endothelial cells and in neurons. The receptor, termed low-density-lipoprotein receptor class A domain containing 3 (LRAD3) (Otsuki et al., 2005), contains an extracellular region composed of three LDLa ligand binding repeats, a transmembrane domain, and a large cytoplasmic domain. Our results reveal that LRAD3 associates with APP and modifies its cellular trafficking, resulting in significant increases in $\mathrm{A} \beta$ production.

\section{Materials and Methods}

Identification and cloning of LRAD3 cDNA. A human EST cDNA clone (358576) was obtained from Genome Systems, which contained significant homology to the human LRP cDNA. EcoRI digestion of the plasmid revealed a 752 bp insert that was completely sequenced. A Lambda Zap II random primed human umbilical vein endothelial cells (HUVECs) cDNA library (generously provided by James Battey, NIH, Bethesda, $\mathrm{MD}$ ) was then screened with the insert that was radiolabeled using a random primer labeling kit (Boehringer Mannheim) and $\left[{ }^{32} \mathrm{P}\right] \mathrm{dCTP}$ (GE Healthcare) that identified four positive clones. These four clones were rescued using the ExAssist Interference-Resistant Helper Phage (Stratagene). pBluescript colonies containing the clone of interest were recovered and partially sequenced, confirming their identity to EST clone 358576. Two of these clones were found to contain the entire coding sequence of LRAD3 and were completely sequenced on both strands. The deduced amino acid sequence of LRAD3 from several species were aligned using Clustal W 2.1 (Larkin et al., 2007).

Cell lines, proteins, antibodies, and expression constructs. COS-1 cells were obtained from American Type Culture Collection. LRP1-deficient Chinese hamster ovary cell lines (CHO 13-5-1) have been described (FitzGerald et al., 1995). HT22, a mouse hippocampal neuron-derived cell line, was a kind gift from D. Schubert (Salk Institute, La Jolla, CA). These cells were maintained in DMEM supplemented with $10 \%$ fetal bovine serum (FBS) and penicillin/streptomycin. To prepare soluble forms of LRAD3, the LRAD3 ectodomain CDNA sequence encoding amino acids 18-161 was cloned into pMT/BiP/V5-His B and expressed using the Drosophila expression system K5130-1 (Invitrogen). Soluble LRAD3 was purified from conditioned media obtained from S2 insect cells transfected with LRAD3 according to the instructions of the manufacturer. Rabbit polyclonal antibodies (Rb585) were raised against soluble LRAD3 and were purified by affinity chromatography using protein G-Sepharose and LRAD3-Sepharose. Cells producing anti-myc antibody 9E10 were obtained from American Type Culture Collection, and IgG was purified using protein-G Sepharose. Rabbit anti-LRP1 polyclonal antibody R2629 has been described (Newton et al., 2005). Anti-APP monoclonal antibodies were purchased from various manufacturers: LN27 (Zymed), 6E10 (Signet), and Jonas (Roche). Human full-length APP695 and APP751 in pHD vector have been described (Ulery et al., 2000). The insert from one of our clones containing full-length LRAD3 was purified after EcoRI digestion and ligated into pcDNA3.1(-) (Invitrogen) (pcDNA-LRAD3). An additional cDNA vector was generated by cloning full-length LRAD3 into pSecTagB (Invitrogen) using the BamHi/HindIII cloning sites with myc tag located at the $\mathrm{N}$ terminus of LRAD3 (pSecLRAD3-Nmyc).

Primary cortical neurons were isolated from E15 CD1 mouse embryos as described (Bacskai et al., 2000). Cortices were triturated with a pipette, and the resulting single-cell suspension was plated onto coverslips coated with poly-L-lysine $(0.1 \mathrm{mg} / \mathrm{ml}$; Sigma-Aldrich $)$ in 24 -well plates and incubated in Neurobasal medium (NBM) (Invitrogen) supplemented with B27 nutrients and 10\% FBS (Thermo Fisher Scientific) and penicillin/streptomycin at $37^{\circ} \mathrm{C}$ for $1 \mathrm{~h}$. After washing, the medium was switched to serum-free NBM supplemented with B27 nutrients. Neuronal cultures were grown at $37^{\circ} \mathrm{C}$, and half of the medium in each well was replaced with new NBM/B27 media every $3 \mathrm{~d}$ according to the protocol of the manufacturer.

Flow cytometry. HT22 cells were grown to $80 \%$ confluence and harvested using a nonenzymatic cell dissociation solution. For cell surface staining, cell pellets $\left(10^{6}\right.$ cells $)$ were washed in PBS and incubated in FACS buffer [HBSS containing $0.5 \%$ bovine serum albumin (BSA)] for $15 \mathrm{~min}$ at $4^{\circ} \mathrm{C}$, followed by incubation with affinity-purified Rb585 antiLRAD3 IgG in FACS buffer $(4 \mu \mathrm{g} / \mathrm{ml})$ for $45 \mathrm{~min}$ on ice. Non-immune IgG was used as a negative control. After washing the cells twice with FACS buffer, the cell pellets were resuspended in FACS buffer containing FITC goat anti-rabbit IgG (1:100) for $45 \mathrm{~min}$. Samples were washed and resuspended in FACS buffer plus propidium iodide $(5 \mu \mathrm{g} / \mathrm{ml})$. Cell staining was measured by flow cytometry using a FACSCalibur with gating on the propidium-iodide-negative cells. For intracellular staining, the cells were fixed in $2 \%$ formaldehyde for $15 \mathrm{~min}$ on ice and then permeabilized with $0.1 \%$ Triton X-100 in PBS-FACS buffer (PBS with $0.1 \%$ BSA) for 10 min. After blocking the nonspecific binding with $1 \%$ goat serum in Triton X-100 containing PBS, cells were stained with anti-LRAD3 IgG and FITC-goat anti-rabbit IgG as mentioned above but in PBS containing $0.1 \%$ Triton $\mathrm{X}-1000$ and $0.1 \%$ goat serum. The cell staining was measured using a FACSCalibur instrument.

RNA isolation and Northern blot hybridization. RNA was isolated from the indicated cell types, and Northern blot hybridization was conducted as described (Ho et al., 2004). A Northern blot containing $2 \mu \mathrm{g}$ of poly $\left(\mathrm{A}^{+}\right) \mathrm{RNA}$ isolated from several human tissues was purchased from Clontech. This blot was probed with the LRAD3 EST using the ExpressHyb system (Clontech) according to the instructions of the manufacturer.

Cell surface antibody binding and internalization. Cell surface binding, internalization, and degradation experiments were performed as described previously (Mikhailenko et al., 1995). COS-1 cells in 12-well tissue culture plates were transiently transfected with the pSecLRAD3Nmyc or the pSecTag plasmids using Fugene 6 (Roche), and internalization experiments were performed at $37^{\circ} \mathrm{C} 40 \mathrm{~h}$ after transfection using 12 $\mathrm{nM}{ }^{125}$ I-labeled $9 \mathrm{E} 10$ antibody in the presence or absence of $500 \mathrm{nM}$ unlabeled 9E10.

Measurement of the endocytic rate constant. COS-1 cells were transiently transfected with $N m y c$ LRP $\beta$ (the LRP light chain) or Nmyc LRAD3. The endocytic rate constant was measured by internalized/surface analysis as described by Wiley and Cunningam (1982) essentially as described previously (Ranganathan et al., 2004). Briefly, transfected cells were incubated with ${ }^{125}$ I-labeled 9E10 (anti-myc monoclonal) for the indicated times. Radioactivity associated with the supernatant (proteinase $\mathrm{K}$ released cell surface $\left.\left[{ }^{125} \mathrm{I}\right] 9 \mathrm{E} 10\right)$ and cell pellet (internalized $\left.\left[{ }^{125} \mathrm{I}\right] 9 \mathrm{E} 10\right)$ was quantified. The endocytic rate, $k_{\mathrm{e}}$, was calculated from the slope of the internalized/bound versus time plot.

Immunohistochemistry. Paraffin-embedded mouse brain slices from male C57BL/6J mice were deparaffinized and immersed in methanol containing $0.3 \% \mathrm{H}_{2} \mathrm{O}_{2}$ for $30 \mathrm{~min}$ to exhaust endogenous peroxidase activity. The sections were then preincubated with $10 \%$ normal goat serum and 1\% BSA (Sigma-Aldrich) in Dulbecco's PBS (DPBS) (Invitrogen) for $20 \mathrm{~min}$, followed by incubation with affinity-purified rabbit anti-LRAD3 IgG (Rb585) for $1 \mathrm{~h}$. The sections were again washed in PBS and incubated with horseradish peroxidase-conjugated anti-rabbit IgG (Vectastain; Vector Laboratories), followed by another PBS wash and developed with chromogen-33-diaminobenzidine tetrahydrochloride (Sigma-Aldrich) for $5 \mathrm{~min}$. Finally, the sections were briefly stained with hematoxylin to stain the nucleus. After mounting the coverslip, the sections were digitally scanned with Scan-Scope (Aperio).

Immunofluorescence microscopy. COS-1 cells were grown on glass coverslips and transfected with pSecLRAD3Nmyc using FuGENE6 transfection reagent (Roche). After $24 \mathrm{~h}$, the cells were washed with PBS and fixed as described (Lee et al., 2006). The fixed cells either were permeabilized with $0.4 \%$ Triton X-100 for 5 min or were not permeabilized. After incubation with anti-LRP $(25 \mu \mathrm{g} / \mathrm{ml})$ antibody or anti-myc antibody (15 $\mu \mathrm{g} / \mathrm{ml}$ ) in $2 \%$ donkey serum, the coverslips were washed with PBS and incubated with secondary antibody for $1 \mathrm{~h}$ at $37^{\circ} \mathrm{C}$. TO-PRO3 (1:500 dilution; Invitrogen) was included in the secondary antibody mixture for nuclear staining. For the HT22 cell lines, cells were grown on coverslips, fixed, permeabilized, and stained with Rb585 IgG and LN27 mouse monoclonal anti-APP IgG. After washing, the coverslips were mounted onto glass slides using FluorSave Reagent (Calbiochem) and viewed with the laser scanning system Radiance 2100 (Carl Zeiss/Bio-Rad). The im- 
ages were captured using the Radiance 2100 software and prepared for publication using Adobe Photoshop software (Adobe Systems).

Expression and purification of soluble $A P P \alpha$. COS- 1 cells were transiently transfected with Myc-tagged soluble APP695 $\alpha$ and APP751 $\alpha$ plasmids. At $24 \mathrm{~h}$ after transfection, cells were placed in serum-free medium, and the serumfree conditioned medium was collected after 30 h. Soluble APP $\alpha$ from the serum-free condition medium was purified using fast protein liquid chromatography using a Mono-Q column (Sepharose). A soluble APP fragment $(\operatorname{sAPP} \alpha)$ was eluted with $20 \mathrm{~mm}$ Tris, $\mathrm{pH}$ 7.5, and $\mathrm{NaCl}(0-1 \mathrm{M}$ linear gradient).

Solid-phase binding assay. Purified $\operatorname{sAPP} \alpha-$ myc was coated on 96-well flat-bottom microtiter plates in Tris-buffered saline (TBS) (50 $\mathrm{mm}$ Tris and $150 \mathrm{~mm} \mathrm{NaCl}$ ) with $2 \mathrm{~mm} \mathrm{CaCl}_{2}$ overnight at $4^{\circ} \mathrm{C}$ and blocked with $1 \% \mathrm{BSA}$ in TBS and $2 \mathrm{~mm} \mathrm{CaCl}_{2}$ for $1 \mathrm{~h}$ at room temperature. The wells were then incubated with increasing concentrations of purified recombinant soluble LRAD3 and anti-myc mouse monoclonal IgG 9E10 in TBS, $2 \mathrm{~mm} \mathrm{CaCl}$, and $0.05 \%$ Tween 20 overnight at $4^{\circ} \mathrm{C}$. Bound LRAD3 was detected with Rb585 IgG $(0.5 \mu \mathrm{g} /$ $\mathrm{ml}$ ) and horseradish peroxidase-conjugated goat anti-rabbit IgG antibody, and bound 9E10 was detected using horseradish peroxidaseconjugated goat anti-mouse IgG antibody. Wells were developed using tetramethylbenzidine peroxidase substrate (KPL), and absorbance was measured at $590 \mathrm{~nm}$.

Coimmunoprecipitation and immunoblot analysis. HT22 cells and mouse brain tissue was lysed in lysis buffer (50 mм Tris, pH 7.4, $150 \mathrm{~mm}$ $\mathrm{NaCl}$, and $1 \%$ Nonidet $\mathrm{P}-40$ ) containing protease (Roche Applied Science) and phosphatase inhibitors (EMD Biosciences). The immunoprecipitation was performed as described (Ranganathan et al., 2004) using Rb585 IgG. Cell lysates were prepared as described above, and, after immunoprecipitation, samples were separated by $4-20 \%$ SDS-PAGE and transferred to nitrocellulose membranes for immunoblot analysis as described (Ranganathan et al., 2004). The bands were visualized with Biomax Light film (Eastman Kodak). For visualizing total LRAD3 expressed, the membranes were stripped using a reblot Western blot recycling kit (Millipore Bioscience Research Reagents) and probed with [ $\left.{ }^{125} \mathrm{I}\right] \mathrm{Rb} 585$ anti-LRAD3 antibodies (1 $\mu \mathrm{g} / \mathrm{ml})$.

A $\beta$ ELISA. LRP-null CHO 13-5-1 cells were transiently transfected with human APP695 or APP751 with or without pcDNA-LRAD3 expression vector. At $24 \mathrm{~h}$ after transfection, the cells were cultured in serum-free medium, and, $24-30 \mathrm{~h}$ later, the conditioned medium was collected for measuring $\mathrm{A} \beta$ and soluble $\mathrm{APP} \alpha$. A $\beta$ levels were measured using the human $\beta$-amyloid 1-40 kit (Biosource) according to the instructions of the manufacturer, and the levels were normalized to total cellular protein. Three independent experiments, each performed in duplicate, were conducted. Cell extracts were blotted for LRAD3 and APP (anti-APP mouse monoclonal antibody 6E10) and GAPDH (rabbit antiGAPDH monoclonal IgG from Cell Signaling Technology), and conditioned media samples were concentrated 100-fold using Strataclean resin (Stratagene) and blotted for $\operatorname{sAPP} \alpha$ using 6E10 antibody. All blots were probed with Li-Cor secondary antibodies and scanned and analyzed using Odyssey imaging software (Li-Cor). The bands were quantified using the same software.

\section{A 1 MWLLGPLCLLLSSAAESQLLP GNNETNE CNI PGNEMCSNGRCI PGAWOCD \\ 51 GLPDCFDKSDEKE PKAKSKCGPTFFPCASG IHCI IGRFRCNGFEDCPDG \\ $101 \frac{*}{\text { SDEENCTANPLIC STARY HCKNGLCIDKSFI CD GQNNCODNSDEESCESS }}$ \\ 151 QEPGSGQVFVT SENQLVYYPS ITYYAIIGSSVIFVLVVALIALVLHHQRKR}

201 NNLMTL PVHRLQH PVLLSRLVVLDHP HHCNVTYNVNNG IQ YVASQAEQNA

251 SEVGSP PSYSEALLDQRPAWYDL PPP PY SSD TE SLNQADL PPYRSRSGSA

301 NSASSQAASSLLSVED TS HSPGQ PGPQE GTAEPRD SEP SQGTEEV
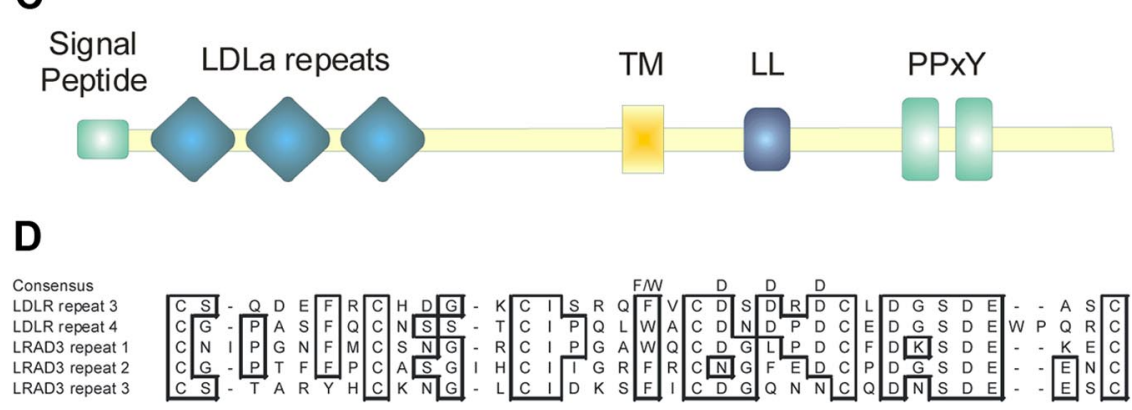

Figure 1. Amino acid sequence and domain organization of LRAD3. A, Deduced amino acid sequence of human LRAD3. Amino acids are numbered from the initiation methionine residue. The putative signal sequence is underlined with a solid line, and the 23 e transmembrane domain is underlined with a dashed line. The three LDLa ligand binding repeats are boxed. N-linked RAD3 predicted to be outside the cell (dashed-dotted line), regions inside the cell (dotted line), and the transmembrane region . Comain organization of LRAD3. The ectodomain contains a signal peptide along with three LDLa repeats. The two polyproline regions (PPXY), which are consensus WW domain and SH3 domain binding motifs. D, Comparison of LRAD3 LDLa repeats with the LDL receptor consensus sequence. The consensus amino acid F/W and three D residues identify amino acids that form an acidic pocket that interact with basic residues on LDLR ligands. Conserved amino acids are boxed.

Pulse-chase experiments. HEK 293 cells were stable transfected with LRAD3. The LRAD3-expressing cells or control HEK 293 cells were transiently transfected with APP695myc and then incubated in methionine and cysteine-free DMEM containing $300 \mu \mathrm{Ci} / \mathrm{ml}\left[{ }^{35} \mathrm{~S}\right]$ methionine/cysteine for $1 \mathrm{~h}$. Cells were lysed immediately (time 0 ) or chased for 1, 2, 3.5, and $5 \mathrm{~h}$. To determine the turnover of APP, APP was immunoprecipitated with mouse monoclonal anti-myc IgG 9E10. The immunoprecipitates were separated on $4-12 \%$ SDS-PAGE and exposed to x-ray film. Band intensities were measured using NIH Image software.

Statistical analysis. The Student's $t$ test was used to analyze for significance between two groups, with $p<0.05$ considered as statistically significant.

\section{Results}

Deduced amino acid sequence of LRAD3

The LRAD3 gene, which is located on chromosome 11 (location: 11p13), encodes a protein of 345 aa (Fig. $1 A$ ). Cleavage by signal peptidase is predicted to occur after serine-17 (Bendtsen et al., 2004), resulting in a 328 aa mature protein with a calculated 


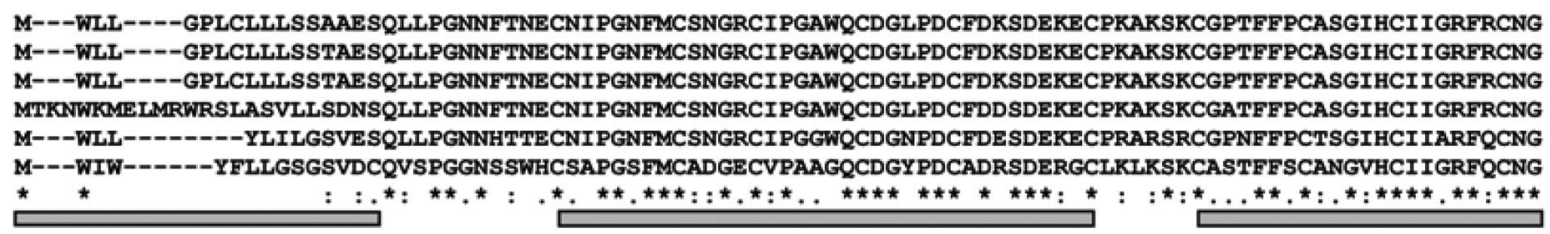

SP

LDLa 1

LDLa 2

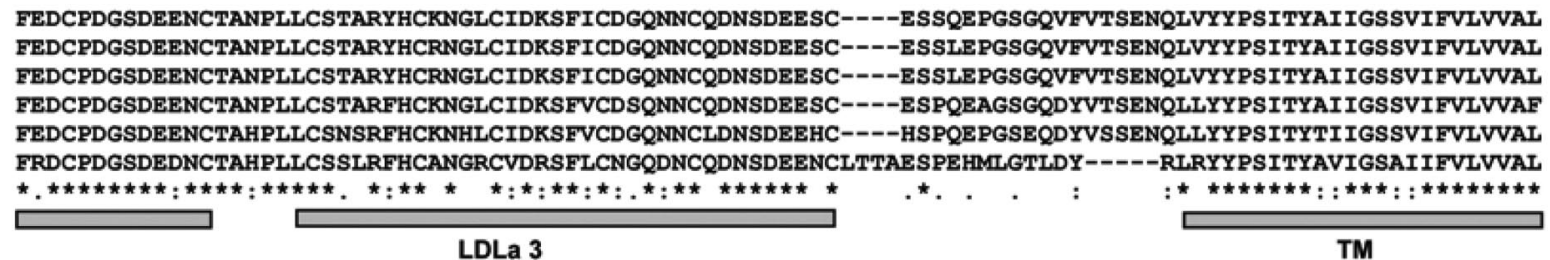

human

rat

mouse

chicken

frog

zebrafish

TM

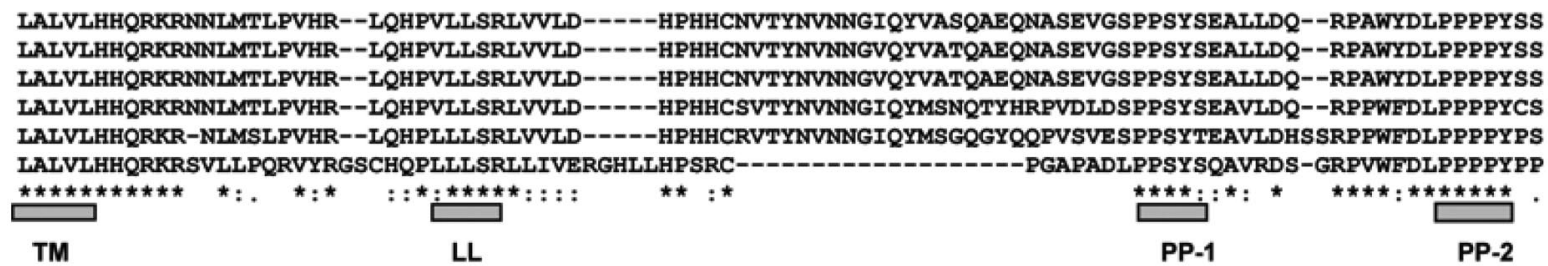

human

rat

mouse

chicken

frog

zebrafish

DTESLNQADLPPYRSRSGSANSASSQAASSLLSVEDT------SHSPGQPGPQEGTAEPRDSEPSQGTE-EV DTESLNQADLPPYRSRSGSAYSASSQAASSLLSVEGS------SHSPEQPGPAESTSEPRDSVPSQGTE-EV DTESLNOADLPPYRSRSGSAYSASSOAASSLLSVEAS------SHNPEOPGSPEGSAEPRDSVPSOGTE-EV ESESPNQPDLPPYRSRTGSMVSPDTPTAGSSLGTDSGWTRDVHESTDGHRTLLERTADPSDSLVNHVDEREV DMESVSQTELPPYRSRTGSSASAGSTEHP--RGTPCG-------TESPTEPQDPTAAPSDDLPSTEVD--V PDREPPGYEEP--------EEPAEAQTQTSVTSVEET------PPAPPSPALPSSSSPPA----------PV

. $\quad$ : * $\quad$. : $\quad$.

\section{human}

rat

mouse

chicken

frog

zebrafish

Figure 2. Alignment of human LRAD3 amino acid sequence with orthologs from other species. The amino acid sequence of LRAD3 from various species were aligned using Clustal W 2.1 , and the extent of identity was determined: rat, 96\%; mouse, $96 \%$; chicken, $81 \%$; frog, $76 \%$; zebrafish, $55 \%$. ${ }^{*}$ denotes residues that are identical; colons denote residues that represent a conserved substitution; periods denote residues that represent a semiconserved substitution. SP, Signal peptide; LDLa1, LDLa2, LDLa3, ligand binding repeats; TM, transmembrane domain; LL, dileucine repeat; PP-1, polyproline repeat 1; PP-2, polyproline repeat 2 .

molecular mass of $36 \mathrm{kDa}$, excluding any contribution of carbohydrates. We used the transmembrane hidden Markov model (TMHMM) (Krogh et al., 2001), which revealed that LRAD3 is also predicted to contain a transmembrane domain beginning at isoleucine 172 and extending to leucine 194 (Fig. $1 \mathrm{~B}$ ). The presence of a signal peptide and a transmembrane domain reveals that LRAD3 is a type 1 transmembrane protein with an extracellular $\mathrm{N}$ terminus and a cytoplasmic $\mathrm{C}$ terminus. The extracellular region of LRAD3 contains three LDLa repeats common to the LDL receptor family as well as two consensus sites for $\mathrm{N}$-linked glycosylation (Fig. 1A). None of the LDLa repeats of LRAD3 contains all of the necessary acidic amino acids that are required for generating an acidic pocket capable of docking lysine side chains that protrude from certain LDL receptor family member ligands, such as the receptor associated protein (RAP) (Fisher et al., 2006) (Fig. 1D), suggesting that potential ligands are likely to be distinct from those that interact with the LDL receptor or LRP1.

The cytoplasmic domain of LRAD3 consists of 151 aa, and, unlike most other members of the LDL receptor family, LRAD3 does not contain NPXY internalization sequences but instead contains a conserved dileucine motif that, when present on other receptors, has been shown to mediate endocytosis (Haft et al., 1994; Hamer et al., 1997). There are four putative phosphorylation sites and two proline-rich stretches within the cytoplasmic domain, which have been implicated in mediating protein-protein interactions (Cohen et al., 1995). LRAD3 is highly conserved among various species (Fig. 2).
LRAD3 is capable of mediating the internalization of ligands To determine whether LRAD3 localizes to the cell surface and has the potential to mediate the internalization of ligands, COS-1 cells were transiently transfected with pSectagLRAD3-Nmyc and then examined by immunofluorescence using anti-myc IgG. Nonpermeabilized cells displayed a prominent cell surface staining for LRAD3 (Fig. 3B). In the same cells, we used an anti-LRP IgG to detect endogenous LRP1, which revealed a more diffuse staining typical of this receptor (Fig. $3 A$ ). When the cells were permeabilized, we detected staining of LRAD3 (Fig. 3E) that overlapped with LRP1 staining (Fig. $3 F$ ). These studies reveal that, in transfected COS-1 cells, LRAD3 is delivered to the cell surface. Immunoblotting experiments confirmed that the antiLRAD3 antibody is specific for LRAD3 and does not cross-react with LRP1 (Fig. 3G).

To determine whether LRAD3 can undergo endocytosis, COS-1 cells transfected with either LRAD3-Nmyc plasmid or empty vector were incubated with $\left[{ }^{125} \mathrm{I}\right] 9 \mathrm{E} 10$, an antibody that selectively recognizes the $m y c$ tag fused to the $\mathrm{N}$ terminus of LRAD3. After transfection, the time course of surface binding or internalization of the iodinated antibody was measured. The results of this experiment indicate that LRAD3-Nmyc-transfected COS- 1 cells bound $\left[{ }^{125} \mathrm{I}\right]$ labeled $9 \mathrm{E} 10$ and internalized this antibody, whereas COS-1 cells transfected with vector alone failed to bind or internalize $\left[{ }^{125} \mathrm{I}\right] 9 \mathrm{E} 10$ (Fig. $3 \mathrm{H}, \mathrm{I}$ ). These results confirm that LRAD3 is delivered to the cell surface and further reveal that LRAD3 is capable of mediating the internalization of ligands. In this and other experiments, no lysosomal-mediated degradation 
of the labeled 9E10 IgG was noted, even after incubations for up to $12 \mathrm{~h}$.

To compare the rates of LRAD3 internalization with that of LRP1, we measured the endocytic rate constant for mycLRAD3 and the LRP1 mini-receptor, myc-LRP1- $\beta$, using ${ }^{125}$ I-labled $9 E 10$ as the ligand for both receptors. Previous studies have demonstrated that LRP1 mini-receptors function like LRP1 to internalize ligands and represent good models for LRP1-mediated endocytosis (Willnow et al., 1994; Mikhailenko et al., 2001). The results (Fig. 3J) reveal that LRP $1-\beta$ has a significantly higher endocytic rate constant $\left(k_{\mathrm{e}}=0.0308 \mathrm{~min}^{-1}\right)$ than that of LRAD3 $\left(k_{\mathrm{e}}=0.0038 \mathrm{~min}^{-1}\right)$. Thus, LRAD3 internalizes ligands at a rate that is approximately eightfold slower than LRP1- $\beta$.

RAP was discovered when LRP1 was purified by ligand affinity chromatography (Strickland et al., 1991). RAP binds tightly to most LDL receptor family members and functions as a molecular chaperone that assists in delivering the receptors to the cell surface (Willnow et al., 1996). We conducted binding experiments to determine whether RAP is recognized by LRAD3. For these experiments, a recombinant molecule expressing the LRAD3 ectodomain was prepared and used to coat microtiter wells. When increasing concentrations of RAP was added to the wells, no specific binding to LRAD3 was detected (data not shown), revealing that LRAD3 does not bind RAP with high affinity.

\section{LRAD3 mRNA expression in human tissues and cell lines}

Northern blot hybridization analysis was performed using RNA isolated from several human tissues and vascular cell types. A single LRAD3 transcript of $\sim 4.2 \mathrm{~kb}$ is expressed at high levels in brain, lung, skeletal muscle, and pancreas (Fig. 4A). LRAD3 mRNA was expressed at moderate levels in heart, placenta, and kidney but was not detected in the liver. The expression of LRAD3 mRNA was also examined in human vascular endothelial cells and smooth muscle cells. LRAD3 mRNA was expressed in both HUVEC and ECV-304, a bladder carcinoma cell line (Fig. $4 B$ ). Lower levels of expression were detected in human saphenous vein and human aortic smooth muscle cells. Interestingly, a smaller-sized LRAD3 transcript is detected in vascular smooth muscle cells (Fig. $4 B$ ) and may correspond to an alternately spliced mRNA, because a BLAST search of the human EST database reveals a transcript derived from several tissues that lacks the first LDLRa repeat, suggesting an alternate splicing of the LRAD3 transcript.

G LRAD3.
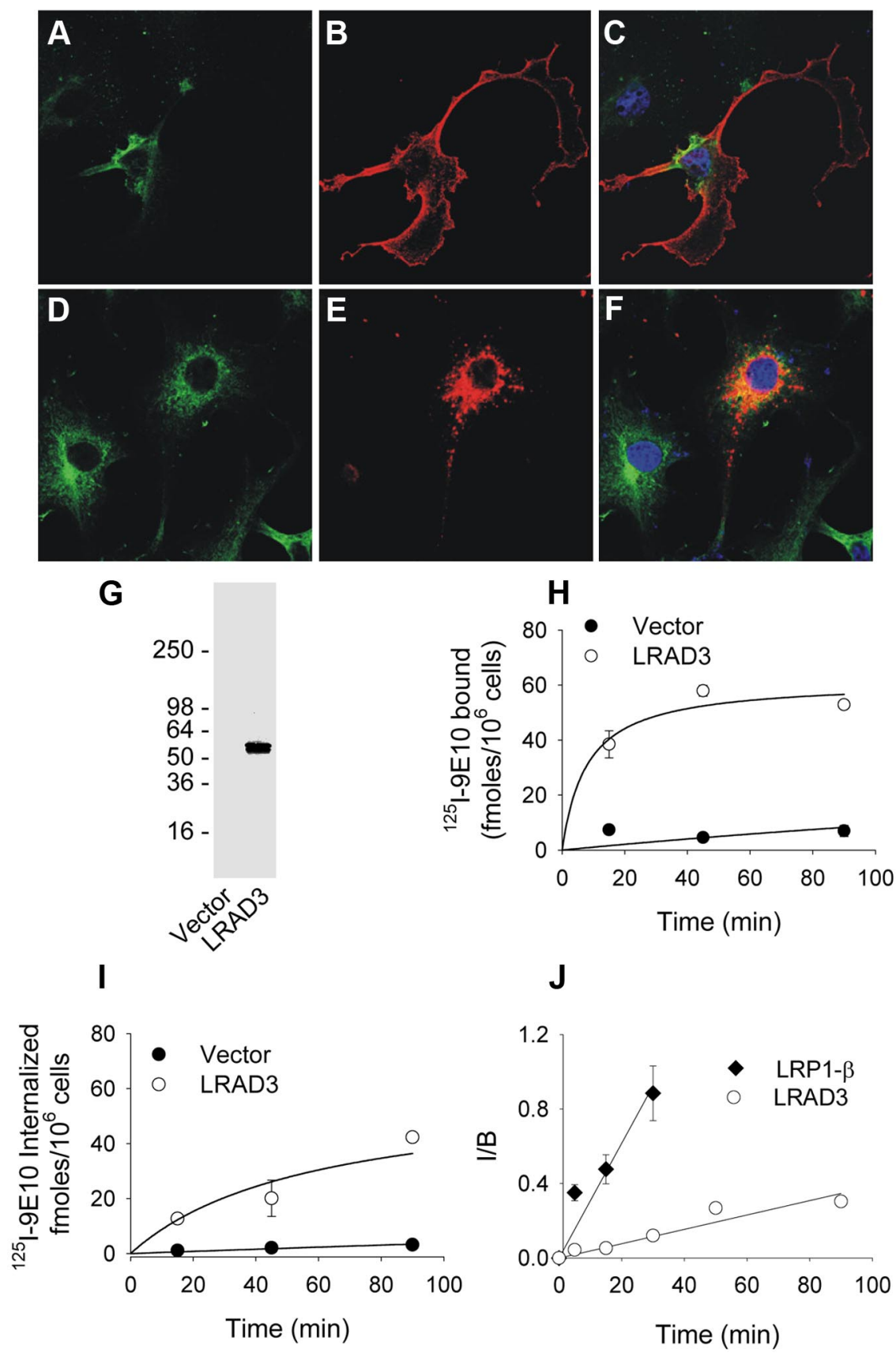

Figure 3. LRAD3 mediates the endocytosis of ligands. Confocal microscopy of COS-1 cells transfected with pSecLRAD3 Nmyc and then stained for $L R A D 3$ using anti-myc $\lg G(B, E)$ or for $\operatorname{LPP}(\boldsymbol{A}, \boldsymbol{D})$. Nuclei are stained with T0-PR03 and are shown in blue in merged images $(\boldsymbol{C}, \boldsymbol{F})$. In $\boldsymbol{A}-\boldsymbol{C}$, the cells were not permeabilized and demonstrate cell surface expression of $\operatorname{LRP}(\boldsymbol{A})$ and $\operatorname{LRAD}(\boldsymbol{B})$. In $\boldsymbol{D}-\boldsymbol{F}$, the cells were permeabilized, showing a punctate intracellular staining of both $\operatorname{LRP}(\boldsymbol{D})$ and $\operatorname{LRAD} 3(\boldsymbol{E}) . \boldsymbol{G}, \operatorname{Immunoblot}$ of COS-1 cell extracts transfected with vector or LRAD3 using anti-LRAD3 IgG demonstrating specificity of the antibody. $\boldsymbol{H}, \boldsymbol{I},{ }^{125}$ I-labeled myc-specific 9E10 antibody was incubated with COS-1 cells transiently transfected with either pSecLRAD3-Nmyc or empty vector, and the amount of surface binding $(\boldsymbol{H})$ and internalized $(\boldsymbol{I})$ radioactivity was measured. $\boldsymbol{J}$, The endocytic rate constant was measured by incubating transfected cells with ${ }^{125} \mathrm{I}$-labeled $9 \mathrm{E} 10$ at $37^{\circ} \mathrm{C}$ for the indicated time periods. After incubation, the cells were placed on ice, and the amount of ligand bound to the surface (B) and internalized (I) was measured. Nonspecific binding and internalization were determined by incubating parallel cultures with excess unlabeled $9 \mathrm{E} 10$ and was subtracted from the total to determine specific binding and internalization. Filled diamonds, Cell transfected with LRP1- $\beta$; open circles, cells transfected with

Immunoblot analysis identifies an $\sim 50 \mathrm{kDa}$ polypeptide in brain membrane extracts

To detect LRAD3 protein in cells and tissues, a recombinant molecule expressing the LRAD3 ectodomain was prepared and used to raise antibodies. The affinity-purified antibodies were used 


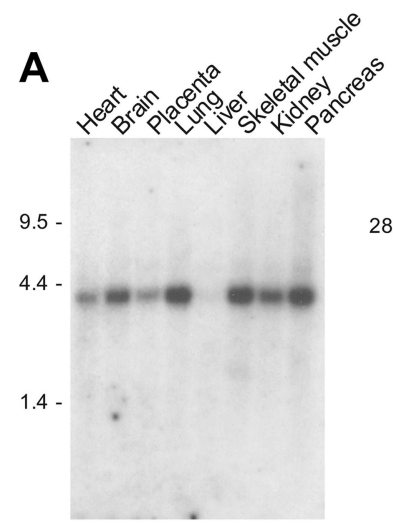

\section{B}

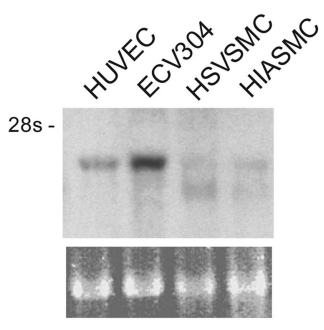

C

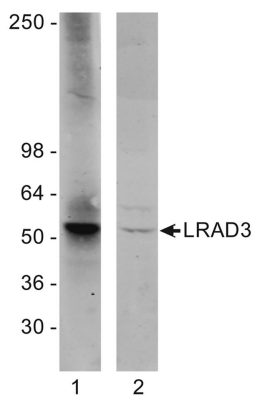

Figure 4. Expression of LRAD3 mRNA and protein in various tissues. $\boldsymbol{A}$, Tissue distribution of LRAD3 mRNA. A purified EcoRl fragment of the human EST clone 358576 was used to probe a human multiple tissue Northern blot. $\boldsymbol{B}$, LRAD3 mRNA expression in human cells. RNA purified from the indicated cell types was probed with ${ }^{32}$-labeled LRAD3 CDNA. In the bottom, a photograph of the 28s rRNA band is shown to demonstrate that equal amounts of RNA were present in each gel lane. The cell sources for RNA are as follows: HUVEC, human umbilical vein endothelial cells; ECV-304, bladder carcinoma cells; HSVSMC, human saphenous vein smooth muscle cells; HIASMC, human iliac artery smooth muscle cells. C, Immunoblot analysis of LRAD3 using affinity-purified Rb585 IgG in pcDNA-LRAD3-transfected COS-1 cell lysates (lane 1). Lane 2 shows an immunoblot of mouse brain membrane lysate. Rb585 lgG binding was detected with goat anti-rabbit IRDye@680 using the Odyssey Infrared Imaging System (Li-Cor).
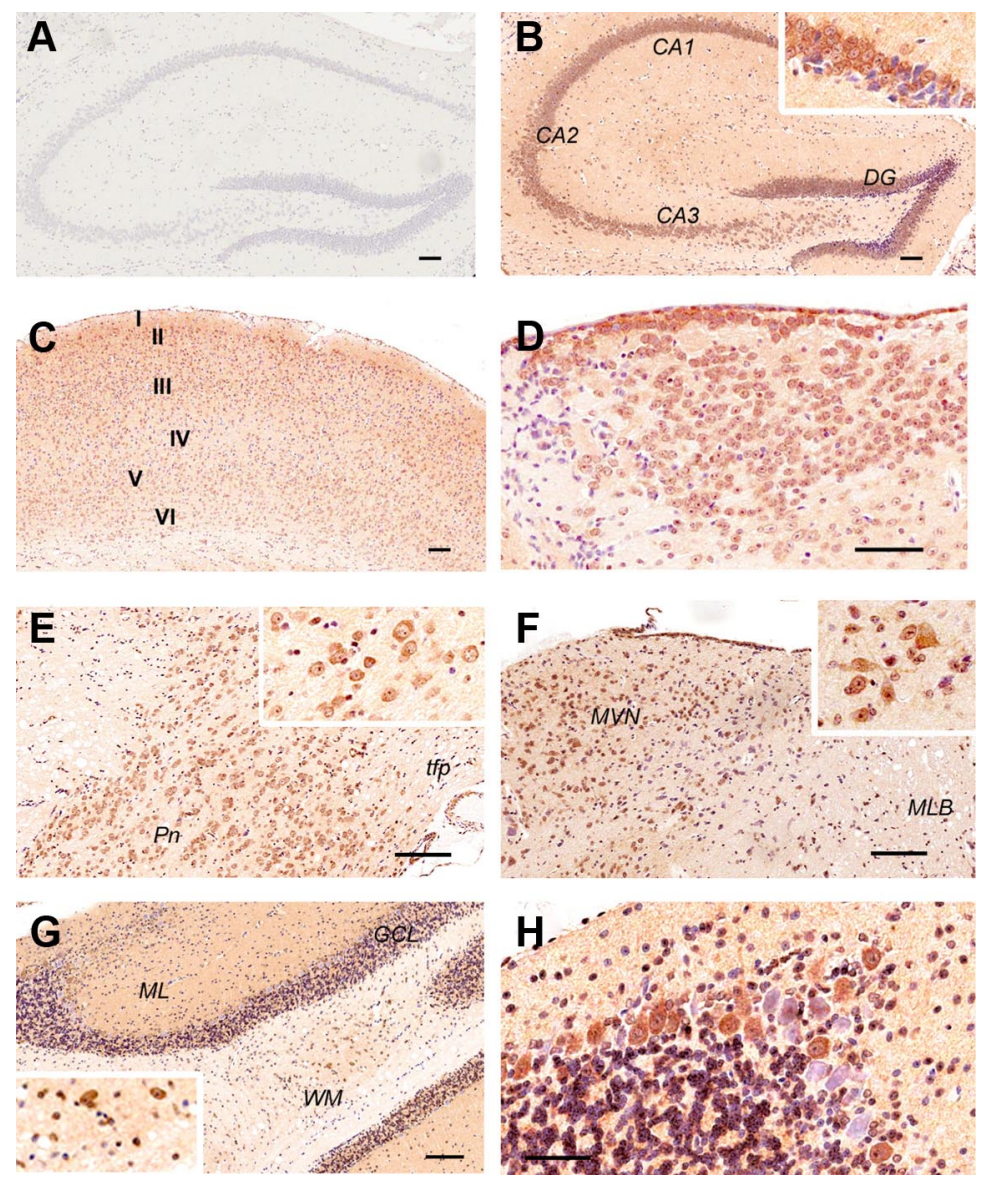

Figure 5. LRAD3 expression in the brain. Coronal sections of adult mouse brain immunostained with anti-LRAD3 antibody. Hippocampus, $\boldsymbol{A}, \boldsymbol{B}$; cerebral cortex, $\boldsymbol{C}$; medial habenular nucleus, $\boldsymbol{D}$; brainstem, $\boldsymbol{E}, \boldsymbol{F}$; cerebellum, $\boldsymbol{G}, \boldsymbol{H}$. Sections using non-immune antibody demonstrates no staining $(\boldsymbol{A})$. All sections are counterstained with H\&E. Insets show enlarged areas demonstrating LRAD3-expressing neurons in the CA1 region (inset in $\boldsymbol{B}$ ), neurons of the pontine nuclei (inset in $\boldsymbol{E}$ ), neurons of medial vestibular nucleus (inset in $\boldsymbol{F}$ ), and neurons in the white matter (inset in $\boldsymbol{G}$ ). LRAD3-positive neurons of granule and molecular layers of the cerebellum as well as Purkinje cells are shown in $\boldsymbol{H}$. CA1, CA2, CA3, Fields of hippocampus; DG, dentate gyrus; $P$, pontine nuclei; $t f p$, transverse fibers of pons; $M V N$, medial vestibular nucleus; $M L B$, medial longitudina bundle; GCL, granule cell layer; ML, molecular layer; WM, white matter. Scale bars: $\boldsymbol{A}-\boldsymbol{C}, \boldsymbol{E}, \boldsymbol{F}, \boldsymbol{H}, 100 \mu \mathrm{m} ; \boldsymbol{D}, \mathbf{G}, 50 \mu \mathrm{m}$.

for immunoblot analysis of membrane extracts from murine brain. The results (Fig. 4C, lane 2) identify an $\sim 50 \mathrm{kDa}$ polypeptide from brain extracts that comigrates with recombinant LRAD3 expressed in COS-1 cells (Fig. 4C, lane 1).

\section{Immunohistochemical analysis of LRAD3 in the brain}

The detection of LRAD3 mRNA in the brain (Fig. 4) prompted us to identify specific regions and cell types in the brain that express LRAD3. For this purpose, immunostaining of paraffin brain sections from adult mice was performed using affinitypurified anti-LRAD3 IgG. No positive staining was observed in brain sections when non-immune control rabbit sera was used (Fig. 5A). In the hippocampus, LRAD3 is found throughout all CA layers. However, the staining appears more prominent in the CA1 layer and in the dentate gyrus (Fig. 5B). LRAD3 is diffusely found in the cerebral cortex, but the staining is more intense in the cortical layers II-III and V (Fig. 5C). We detected intense staining in neurons of the medial habenular nucleus (Fig. 5D). In the brainstem, staining is evident in both the pontine nuclei (Fig. $5 E$ ) and the medial vestibular nucleus (Fig. $5 F$ ). In the cerebellum, the staining is particularly intense in the granular layer (Fig. 5G). However, LRAD3 staining is also detected in some Purkinje and molecular layer cells (Fig. $5 H$ ).

LRAD3 staining of isolated cortical neurons that were not permeabilized confirmed cell surface staining in these neurons (Fig. $6 \mathrm{~A}-\mathrm{C}$ ). A punctuate intracellular staining pattern was observed in cells that were permeabilized (Fig. $6 D-F$ ). The results shown in Figure 6 further highlight that not all of the neurons in culture seem to express LRAD3.

\section{LRAD3 coimmunoprecipitates with APP}

Because LRAD3 is prominently expressed in neurons of the hippocampus CA1 layer, a region of the brain that is relevant to Alzheimer's disease, we initiated studies to determine whether LRAD3 can influence the cellular processing of APP, a protein genetically implicated in the development of Alzheimer's disease. We found that the widely used mouse hippocampal neuronal cell line HT22 expresses LRAD3. The expression of LRAD3 in these cells was confirmed by both immunoblotting (Fig. 7A, lane 2) and FACS analysis (Fig. $7 B, C$ ). Immunofluorescence microscopy of HT22 cells revealed a punctate staining pattern for 
LRAD3 (Fig. 7D) and APP (Fig. 7E). Although APP and LRAD3 do have distinct staining patterns, there is significant colocalization of LRAD3 with APP as evidenced from the merged image (Fig. $7 F$ ).

To examine the potential of LRAD3 and APP to interact, endogenous LRAD3 was immunoprecipitated from mouse brain extracts. After separation of the proteins by SDS-PAGE, the presence of APP in the immunoprecipitate was investigated by immunoblot analysis. The results of this experiment, shown in Figure $8 A$, reveal that APP coimmunoprecipitates with LRAD3 from mouse brain extracts. Endogenous APP was also observed to coimmunoprecipitate with LRAD3 in HT22 cells (Fig. $8 B$ ). To examine the specificity of the interaction, we immunoprecipitated LRAD3 from HT22 cell extracts and probed the immunoprecipitate for transferrin receptor. These experiments revealed that the transferrin receptor failed to coimmunoprecipitate with LRAD3 (Fig. $8 C$ ), suggesting that the interaction of LRAD3 with APP is specific.

To determine whether APP precipitation resulted in coprecipitation of LRAD3, we used a model system in which COS-1 cells were cotransfected with LRAD3 and APP751. COS-1 cells were selected because they do not express endogenous LRAD3. In the first part of this experiment, COS-1 cells were cotransfected with vector and LRAD3 or with APP751 and LRAD3. After transfection, APP751 was immunoprecipitated, and the immunoprecipitated proteins probed for LRAD3 (Fig. 8D). The results confirm that LRAD3 coimmunoprecipitated with APP751. Cell extracts were also subjected to immunoprecipitation with antibodies against LRAD3, and the immunoprecipitated proteins were probed for APP751. The results (Fig. 8E) confirm that APP751 coimmunoprecipitated with LRAD3. Together, all of these results suggest a specific interaction between LRAD3 and APP and further reveal that the order of immunoprecipitation does not alter the outcome.

To identify the portion of APP required for its interaction with LRAD3, we first examined a potential interaction of soluble forms of APP released by the action of $\alpha$-secretase $(\operatorname{sAPP} \alpha)$ with the soluble LRAD 3 ectodomain using solid-phase binding assays. In this assay, we coated the microtiter wells with purified sAPP $\alpha$ containing a myc epitope and incubated the coated microtiter wells with increasing concentrations of soluble recombinant LRAD3 (sLRAD3). Coating of the microtiter wells with sAPP $\alpha 751-$ myc was confirmed by incubating with increasing concentration of 9E10 anti-myc IgG. As shown in Figure 9A, we did not observe any direct association between $\operatorname{sAPP} \alpha$ and sLRAD3. However, when we transiently coexpressed LRAD3 and C99 (a 99-aa C-terminal fragment that contains the intact A $\beta$ sequence and the cytoplasmic tail that results from $\beta$ secretase
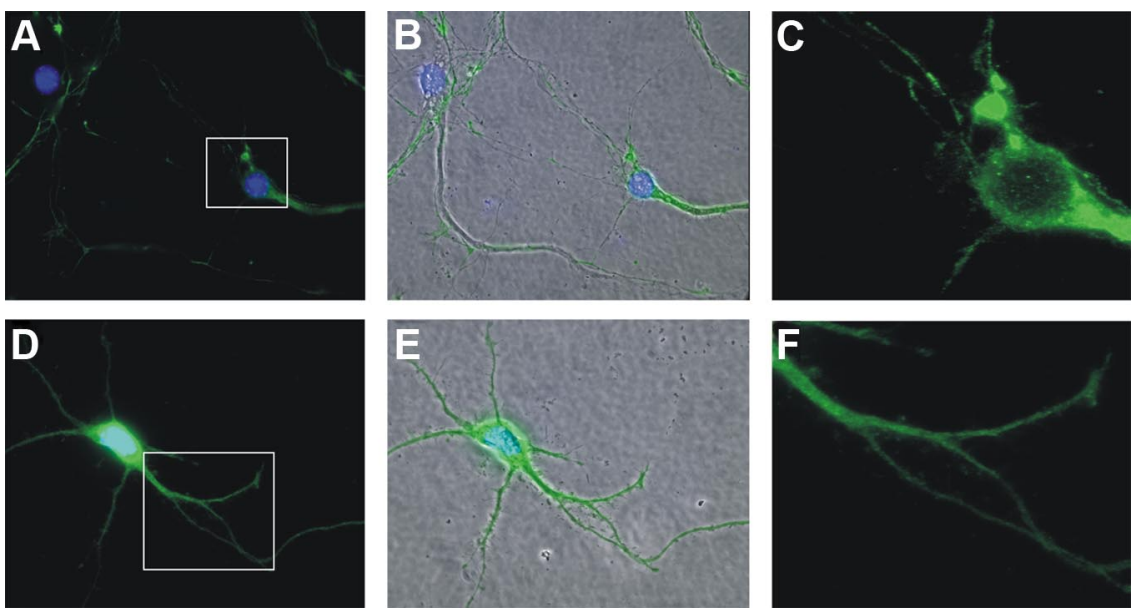

Figure 6. Expression of LRAD3 in cultured cortical neurons. Embryonic day 15 neurons were grown for $7 \mathrm{~d}$ and then stained with affinity-purified Rb585 IgG and Alexa Fluor 488 anti-rabbit lg G to visualize LRAD3 expression. DAPI was used to detect the nucleus. The cells in $\boldsymbol{A}$ - $\boldsymbol{C}$ were not permeabilized, whereas the cells in $\boldsymbol{D}-\boldsymbol{F}$ were permeabilized. $\boldsymbol{B}$ and $\boldsymbol{E}$ show a merged fluorescence image with the phase-contrast image. $\boldsymbol{C}$ and $\boldsymbol{F}$ are high magnification of sections of $\boldsymbol{A}$ and $\boldsymbol{D}$, respectively and demonstrate that LRAD3 forms a punctate pattern in $\boldsymbol{F}$. The image were taken with a $100 \times$ objective.
A

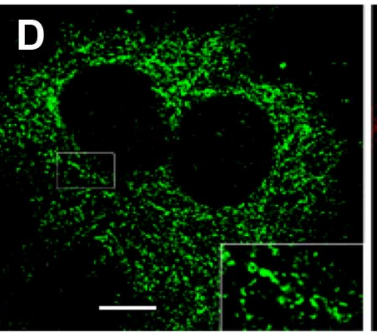

B

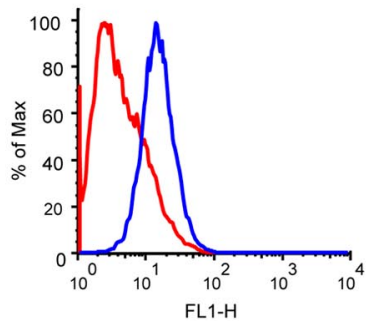

FL1-H

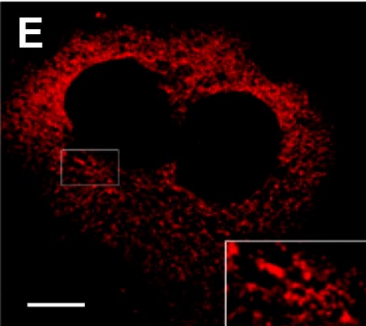

C
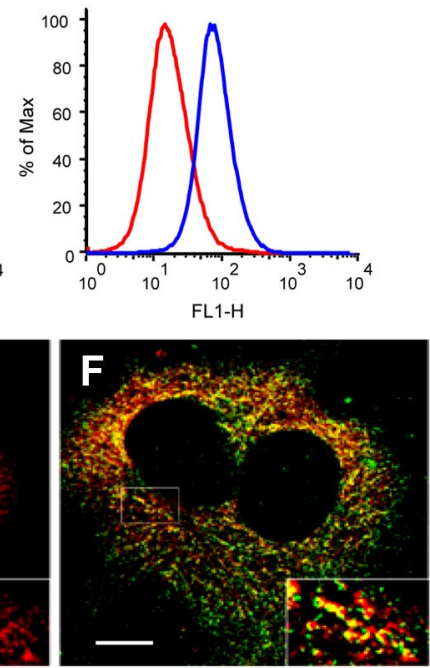

Figure 7. LRAD3 is expressed on the cell surface of the HT22 hippocampal neuronal-derived cell line and colocalizes with APP. $\boldsymbol{A}$, Immunoblot of LRAD3 in LRAD3-transfected COS-1 cell lysates (lane 1) and HT22 cell lysates (lane2). B, C, FACS analysis showing 列 control staining (red lines) are shown. $\boldsymbol{D}-\boldsymbol{F}$, Confocal microscopy analysis for LRAD3 (D) and APP (E). F shows the merged images of LRAD3 and APP. Insets show enlarged image of the indicated regions. Scale bars, $10 \mu \mathrm{m}$.

cleavage) in COS- 1 cells, we noted that this fragment of APP coimmunoprecipitated with LRAD3 (Fig. 9B, lane 2, top). Together, these experiments reveal that the determinant for the interaction between APP with LRAD3 resides within the C99 fragment and not within the large ectodomain that is released during $\alpha$-secretase cleavage.

The LRAD3 cytoplasmic domain contains a polyproline sequence (PPPPY) that is recognized by WW-domain-containing proteins. Fe65, which contains a WW domain, is expressed in the brain and associates with APP via a PTB domain and modulates its signaling properties (Cao and Südhof, 2001). Although the polyproline sequence in LRAD3 is not the optimal motif for the Fe65 WW domain, given the importance of Fe65 in APP biology, we performed a coimmunoprecipitation experiment to determine whether Fe65 is capable of associating with LRAD3. Our 

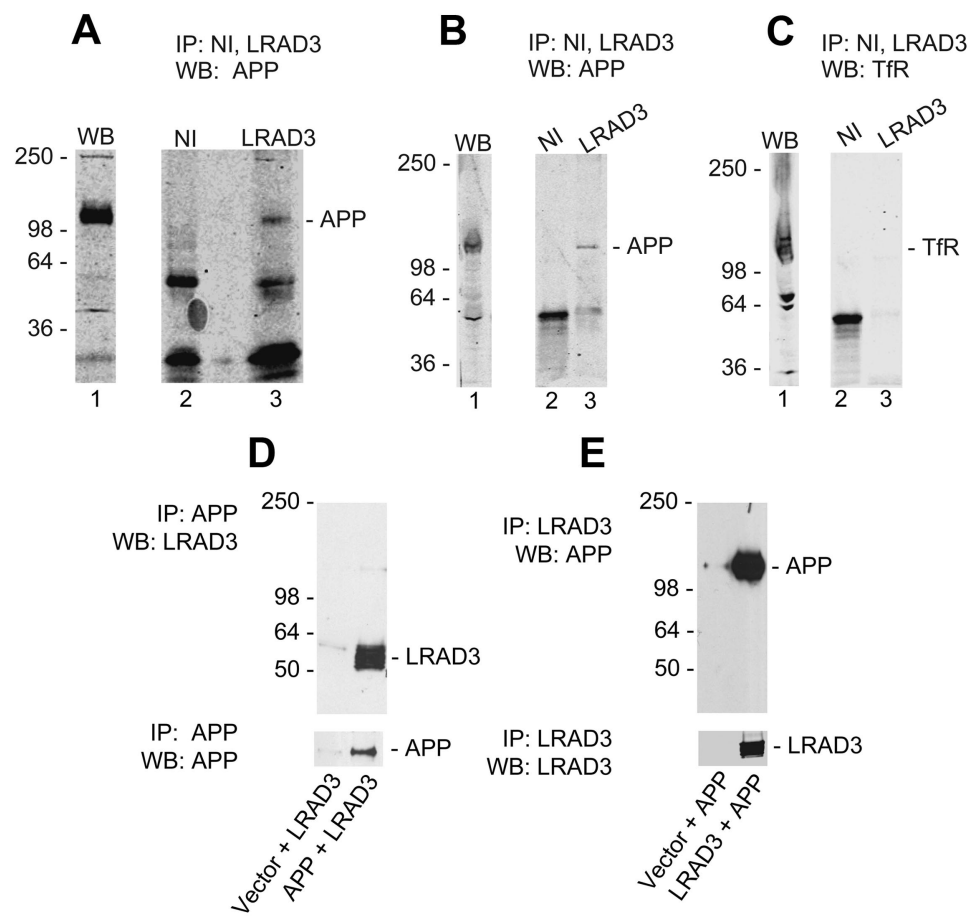

Figure 8. Coimmunoprecipitation experiments reveal an interaction between LRAD3 and APP. Mouse brain $(\boldsymbol{A})$ and HT22 cell (B) lysates were subjected to immunoprecipitation using non-immune lgG (NI) (lane 2) or anti-LRAD3 Rb585 IgG (LRAD3) (lane 3). The immunoprecipitates were separated on 4-12\% SDS-PAGE under reducing conditions and transferred to nitrocellulose membrane and analyzed for APP using LN27 antibody. Lane 1 represents an immunoblot of brain extract and HT22 cell lysates with LN27 IgG, respectively. C, Immunoprecipitation of HT22 cell lysates with NI (lane 2) or anti-LRAD3 lgG (lane 3), followed by immunoblotting for the transferring receptor (TfR). Lane 1 represents an immunoblot of HT22 cell lysates with anti-TfR IgG. D, COS-1 cells were transiently transfected with empty vector and LRAD3 (left lane) or APP751 and LRAD3 (right lane) for $48 \mathrm{~h}$. Cell lysates were then immunoprecipitated with anti-APP IgG and then immunoblotted with anti-LRAD3 to detect the coimmunoprecipitated LRAD3. The immunoblots were also reprobed with anti-APP to detect APP in the immunoprecipitate. E, COS-1 cells were transiently transfected with empty vector and APP (left lane) or LRAD3 and APP751 (right lane) for $48 \mathrm{~h}$. Cell lysates were then immunoprecipitated with anti-LRAD3 IgG and then immunoblotted with anti-APP to detect the coimmunoprecipitated APP. The immunoblots were also reprobed with anti-LRAD3 to detect LRAD3 in the immunoprecipitate. IP, Immunoprecipitation; WB, Western blot.

this process. As indicated in Figure $10 \mathrm{~B}$, coexpression of LRAD3 with either the APP695 or APP751 isoforms in these cells results in a decrease in the levels of sAPP $\alpha$ detected in the media, confirming that LRAD3 affects the processing of both APP751 and APP695. The results were quantified and expressed as sAPP $\alpha$ levels normalized to the total APP in the cells and demonstrate a significant effect of LRAD3 expression on the production of sAPP $\alpha$ from both APP695 and APP751 isoforms (Fig. 10C). Thus, LRAD3 expression appears to reduce the nonamyloidogenic processing of APP.

To determine whether LRAD3 alters the production of the $\mathrm{A} \beta$ peptide as might be expected from the results of Figure $10 A-C$, an ELISA was performed on conditioned media after cotransfection of LRAD3 and APP in CHO 13-5-1 cells. The results reveal that $\mathrm{CHO} 13-5-1$ cells expressing LRAD3 produce significantly more $\mathrm{A} \beta_{40}$ than cells transfected with vector alone (Fig. $10 D$ ). The increase in $\mathrm{A} \beta_{40}$ cannot be attributed to an increase in the expression of APP, because the total levels of APP in the transfected cells were similar (Fig. 10B, middle). Finally, it should be highlighted that the effect of LRAD3 on $\mathrm{A} \beta$ production was observed with both isoforms of APP (i.e., APP751 and APP695).

To further characterize the role of LRAD3 in APP processing, we performed metabolic labeling experiments to mea-

findings reveal that Fe65 does not effectively coimmunoprecipitate with LRAD3, and, furthermore, we found that the association between LRAD3 and APP was not affected by the presence or absence of FE65 (data not shown).

\section{LRAD3 modulates the cellular processing of APP}

To examine whether the potential of LRAD3 to interact with APP may modulate the cellular trafficking and proteolysis of APP, we evaluated the effect of LRAD3 expression on total levels of cellular APP and secreted sAPP $\alpha$ (derived from the activity of $\alpha$-secretase) in conditioned medium. Initially, COS- 1 cells were transfected with LRAD3, and the effect of LRAD3 expression on levels of endogenous sAPP in conditioned media was measured by immunoblot analysis. A decrease in the levels of sAPP derived from proteolysis of endogenously expressed APP was observed in conditioned media from COS- 1 cells that were transfected with LRAD3, but no change in total APP levels was noted (Fig. 10A). These results suggest that expression of LRAD3 affects the processing of endogenous APP, and similar results were obtained in other cells, such as H4 neuroglioma cells (data not shown). Next, we used CHO 13-5-1 cell lines that are known to be deficient in LRP1 (FitzGerald et al., 1995), another receptor that influences APP proteolytic processing (Ulery et al., 2000). Because LRP1 is known to increase the production of $A \beta$ peptide (Ulery et al., 2000; Pietrzik et al., 2002), LRP1-deficient cell lines were chosen to eliminate any possible contribution of LRP1 to sure the turnover of APP by using $\left[{ }^{35} \mathrm{~S}\right]$ methionine/cysteine. For these experiments, we generated stable transfectants of LRAD3 in HEK 293 cells, which have been used previously to investigate the trafficking of APP (Borg et al., 1998). These cells and control HEK 293 cells were first transiently transfected with myc-APP695 and then incubated for $1 \mathrm{~h}$ at $37^{\circ} \mathrm{C}$ with $\left[{ }^{35} \mathrm{~S}\right]$ methionine/cysteine to metabolically label cellular proteins. After this incubation, the media was replaced with unlabeled methionine/cysteine and the fate of labeled APP followed with time. The results of this experiment, shown in Figure $10 \mathrm{E}$, demonstrate an increased turnover of APP695 in cells expressing LRAD3. The half-life of APP695 in control HEK 293 cells was $2.6 \mathrm{~h}$, a value that is consistent with previous studies (Borg et al., 1998). In contrast, the half-life of APP695 in HEK 293 cells expressing LRAD3 was reduced to $1.3 \mathrm{~h}$ (Fig. 10F).

\section{Discussion}

In the current study, we identify a new member of the LDL receptor family, LRAD3, which is expressed in neurons within the hippocampus, a region that is affected during the early stages of Alzheimer's disease. Confocal microscopy reveals that some LRAD3 immunofluorescence overlaps with APP fluorescence, suggesting localization within the same or closely opposed cellular compartments in HT22 cells. Coimmunoprecipitation experiments reveal that APP is capable of interacting with LRAD3. This interaction also occurs with a truncated version of the APP mol- 
A

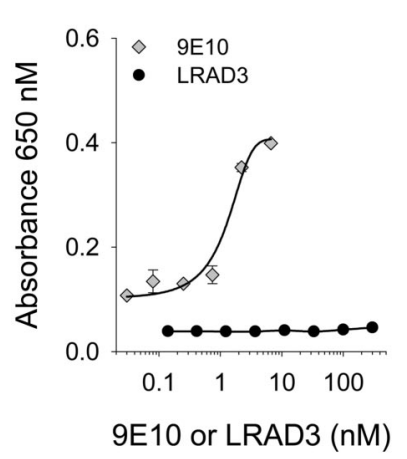

B

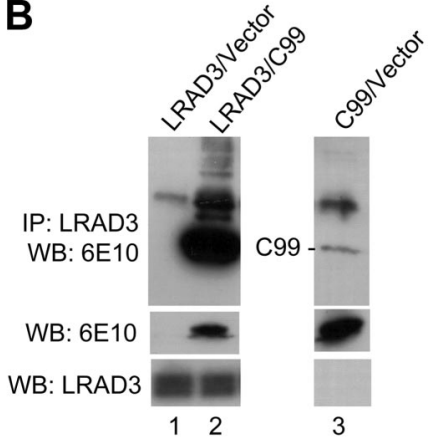

9E10 or LRAD3 (nM)
A

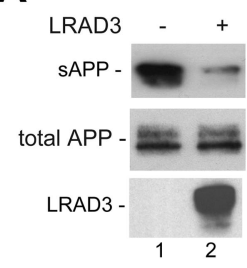

B

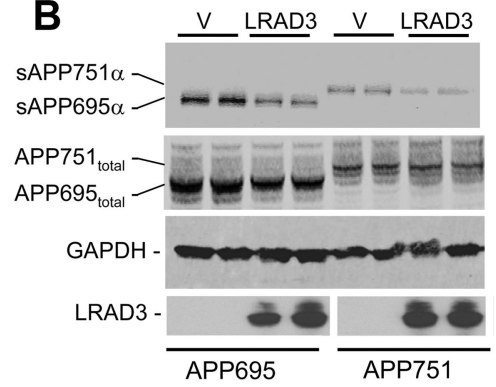

D

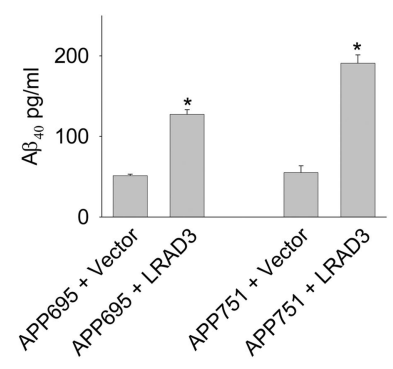

C

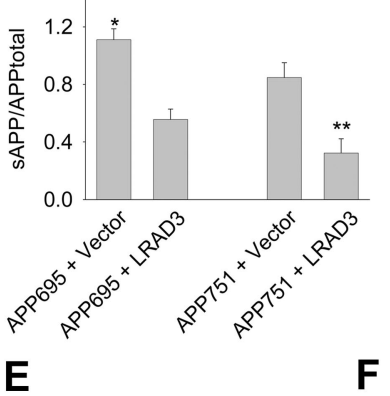

$\mathbf{F}$
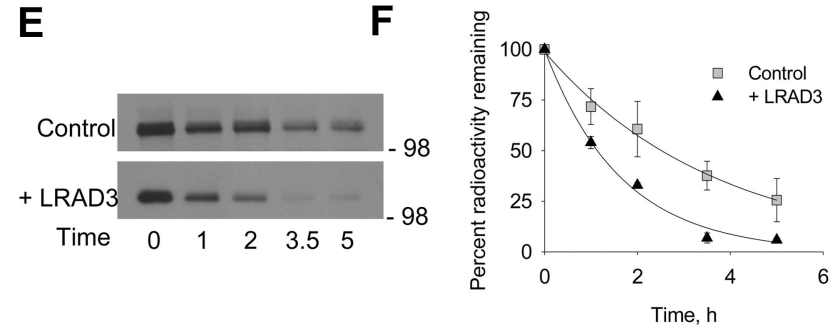

Time, $\mathrm{h}$
Figure 9. LRAD3 interacts the C99 APP fragment. $\boldsymbol{A}$, Increasing concentrations of soluble LRAD3 were added to microtiter wells coated with soluble myc-APP751 $\alpha$ (circles). Bound LRAD3 was detected using anti-LRAD3 Rb585 lgG and horseradish peroxidase-conjugated goat anti-rabbit IgG antibody. To detect the immobilized soluble APP on the plate, increasing concentrations of the anti-myc IgG 9E10 was used (diamonds). $\boldsymbol{B}$, COS-1 cells were transiently transfected with pcDNA-LRAD3 and vector (lane 1), pCDNA-LRAD3/C99 (lane 2), or empty vector/C99 (lane 3) in the presence of $10 \mathrm{~nm} \gamma$-secretase inhibitor. After transfection, cell extracts were subjected to immunoprecipitation with anti-LRAD3 and immunoblotted with 6 E10 $\operatorname{lgG}$. The samples in lanes 1-3 were run on the same gel.

ecule termed C99 that contains the intracellular domain (ICD), the transmembrane domain, and a short extracellular sequence of APP but not with $\mathrm{sAPP} \alpha$, revealing that the large ectodomain of APP is not required for the interaction between APP and LRAD3. We further demonstrate that LRAD3 expression alters APP processing, such that lowered levels of sAPP $\alpha$ and increased amounts of the $\mathrm{A} \beta$ peptide are secreted into the media when LRAD3 is expressed. Finally, we demonstrate that expression of LRAD3 significantly increases the turnover of APP. The mechanism by which LRAD3 modulates the trafficking and processing of APP is not known but could result from a direct interaction with APP that might be expected to alter its cellular trafficking, such as enhancing its recycling through endosomal compartments in which proteolysis can occur. Although LRAD3 has polyproline motifs that are predicted to interact with WW-domain-containing proteins, they are not recognized by Fe65, a protein that also associates with APP and modulates its cellular trafficking (Sabo et al., 1999).

The cellular trafficking of APP is complex, because APP undergoes regulated intramembrane proteolysis (Brown et al., 2000). This is a process in which an integral membrane protein is cleaved within its transmembrane domain after shedding of the ectodomain. In the case of APP, the initial shedding event occurs via the activity of an $\alpha$ - or $\beta$-secretase, followed by cleavage within the transmembrane domain mediated by a $\gamma$-secretase activity. Proteolysis by the $\beta$ - and $\gamma$-secretase is thought to occur within the endosomal compartments (Sisodia and Price, 1995). The $\beta$-secretase has been identified as a transmembrane aspartylproteinase termed BACE (Vassar et al., 1999), whereas the $\gamma$-secretase has been identified as presenillin 1 or 2 (De Strooper et al., 1999) along with several other proteins that form the enzyme complex (De Strooper, 2003). The presenilin-mediated cleavage of APP occurs within the transmembrane domain and releases the APP ICD, which is thought to participate in signaling pathways via association with the adaptor protein Fe65 and the histone acetyltransferase Tip60 (Cao and Südhof, 2001). Enhanced proteolytic processing of APP when LRAD3 is expressed thus raises the possibility that LRAD3 might influence the signaling properties of APP as well.
Figure 10. LRAD3 expression modulates APP processing. $A, C O S-1$ cells were transfected with empty vector (lane 1) or pcDNA-LRAD3 (lane 2) and were then placed in serum-free medium. After $24 \mathrm{~h}$, conditioned medium was collected and concentrated, and proteins were separated on 4-12\% SDS PAGE. After transfer to nitrocellulose membranes, the proteins were probed for soluble APP using LN27 antibody. Total APP was detected in cell extracts. The LRAD3 immunoblot was run on separate gels. B, CH0 13-5-1 cells were cotransfected with APP 695 or APP751 along with pCDNA-LRAD3 or empty vector (V) and cultured for $24 \mathrm{~h}$, before placing in a serum-free medium. The cells were incubated for $24 \mathrm{~h}$ in serum-free media, and the conditioned medium then collected and assayed for soluble APP by immunoblotting with 6 E10 (top). Cell extracts were also analyzed by immunoblot for total APP (middle) or GAPDH (bottom). $C$, Bands shown in $\boldsymbol{B}$ were quantified using Odyssey imaging software, and the ratio of sAPP $\alpha$ to total APP was calculated. ${ }^{*} p=0.0008$, three independent experiments, each performed in duplicate; ${ }^{* *} p=0.006$, three independent experiments, each performed in duplicate. $\boldsymbol{D}$, Conditioned medium from the experiment detailed in $\boldsymbol{B}$ were collected and analyzed for $A \beta_{1-40}$ levels using ELISA. ${ }^{*} p=0.00001$, three independent experiments, each performed in duplicate; ${ }^{* *} p=0.00005$, three independent experiments, each performed in duplicate. $\boldsymbol{E}, \boldsymbol{F}$, Turnover of full-length APP 695-myc in HEK 293 cells stably transfected with LRAD3 (+ LRAD3) or control HEK 293 cells (Control). The cells were pulse labeled with [ ${ }^{35}$ S]methionine/cysteine for $1 \mathrm{~h}$ and chased for $0,1,2,3.5$, and $5 \mathrm{~h}$. $\boldsymbol{F}$, The half-life was determined by quantifying the results from $\boldsymbol{E}$. Three independent experiments were performed, each in duplicate, and a representative experiment is shown.

As a member of the LDLR family, LRAD3 has some interesting structural features. The three LDLa repeats in the ectodomain are homologous to those found in LRP and other members of the LDL receptor family, but none have the three conserved, calcium-coordinating acidic residues that were found to encircle lysine residues present on LRP ligands (Fisher et al., 2006). This accounts for the fact that LRAD3 fails to bind RAP with high affinity. The LDLa repeats of LRP, megalin, and the LDL receptor are responsible for binding ligands. Thus, although ligands that may interact with LRAD3 are unknown at present, it seems likely that LRAD3 will recognize ligands distinct from other members of the LDL receptor family. Given the structure of the LRAD3 
cytoplasmic domain, it also seems likely that ligand binding may trigger signaling events. Interestingly, several ligands that are capable of interacting with LRP are also thought to initiate signaling events. These ligands include activated $\alpha_{2} \mathrm{M}$ (Misra et al., 1994), urokinase-type plasminogen activator (Nguyen et al., 1998), apoE (Riddell et al., 1997), and tissue-type plasminogen activator (Hu et al., 2006). Whether or not any of these molecules are ligands for LRAD3 remains to be determined.

LRAD3 also lacks the EGF and $\beta$-propeller domains that are found in the extracellular portions of LDL receptor family members that are important for $\mathrm{pH}$-induced uncoupling of ligands within acidic endosomal compartments (Davis et al., 1987; Mikhailenko et al., 1999; Rudenko et al., 2002). Interestingly, the structural organization of LRAD3 is similar to that of two alternately spliced genes from the quail, pg800 and pg950, encoding receptors for the subgroup A Rous sarcoma virus (Bates et al., 1993). pg950 contains a single LDLa repeat, a transmembrane domain, and a short cytoplasmic domain, whereas pg800 lacks the cytoplasmic domain. Thus, LRAD3, pg800, and pg950 may define a new subfamily of receptors that are closely related to the LDL receptor by the presence of one or more LDLa repeats in their extracellular domains but lack the other LDL receptor family motifs.

In addition to its extracellular complement-like repeats, LRAD3 contains a transmembrane domain and a 151 aa cytoplasmic domain. Unlike other members of the LDL receptor family, LRAD3 lacks an NPXY clathrin internalization sequence. Instead, the cytoplasmic domain of LRAD3 contains a conserved dileucine motif that has been demonstrated to mediate endocytosis and sorting of many receptors, including CD3 (Letourneur and Klausner, 1992), IgG Fc receptors (Hunziker and Fumey, 1994), the IL-6 receptor (Dittrich et al., 1996), and CD44 (Sheikh and Isacke, 1996). The Drosophila yolkless gene, which encodes an LDL receptor homolog, also contains dileucine motifs (Schonbaum et al., 1995). Our experiments indicate that LRAD3 appears capable of mediating the endocytosis of a radiolabeled antibody directed against a $m y c$ epitope placed at the $\mathrm{N}$ terminus of this protein.

The cytoplasmic domain of LRAD3 also contains two polyproline sequences, SPPSY and PPPPY, which represent consensus sequences that are recognized by WW-domain-containing proteins (Sudol, 1996; Pawson and Scott, 1997). WW domains are small modules of 35-40 aa that are characterized by four well conserved aromatic residues of which two are tryptophans that bind to proteins containing a minimal consensus sequence of XPPXY (Bork and Sudol, 1994; Chen and Sudol, 1995). The list of proteins that contain WW domains is expanding, and many of these molecules appear to be involved in regulatory or cell signaling processes (Sudol, 1996; Pawson and Scott, 1997). Although the results obtained in the present study reveal that Fe65 does not interact with LRAD3, it is likely that other WW-domaincontaining proteins will be identified that do interact with the LRAD3 cytoplasmic domain. Interestingly, not only does the PPPPY sequence in LRAD3 conform to the WW domain binding consensus, but this region may also be recognized by molecules containing Src homology 3 (SH3) domains (Cohen et al., 1995; Pawson, 1995; Pawson and Scott, 1997).

In summary, we have identified a novel transmembrane receptor containing three LDLa repeats in its extracellular domain that is abundant in the brain, especially regions associated with the early development of Alzheimer's disease. LRAD3 colocalizes with APP within these regions of the brain and is able to associate with APP. Transfection of LRAD3 into cells expressing APP re- veal that LRAD3 alters the proteolytic processing such that increased amounts of $\mathrm{A} \beta$ are produced along with decreased amounts of sAPP $\alpha$. Given that $\mathrm{A} \beta$ deposition is thought to represent an initiating event in Alzheimer's disease, it is possible that LRAD3 may modulate the development and progression of this disorder.

\section{References}

Bacskai BJ, Xia MQ, Strickland DK, Rebeck GW, Hyman BT (2000) The endocytic receptor protein LRP also mediates neuronal calcium signaling via $N$-methyl-D-aspartate receptors. Proc Natl Acad Sci U S A 97:11551-11556.

Bates P, Young JA, Varmus HE (1993) A receptor for subgroup A Rous sarcoma virus is related to the low density lipoprotein receptor. Cell 74:1043-1051.

Bendtsen JD, Nielsen H, von Heijne G, Brunak S (2004) Improved prediction of signal peptides: SignalP 3.0. J Mol Biol 340:783-795.

Borg JP, Yang Y, De Taddéo-Borg M, Margolis B, Turner RS (1998) The X11alpha protein slows cellular amyloid precursor protein processing and reduces Abeta40 and Abeta42 secretion. J Biol Chem 273:14761-14766.

Bork P, Sudol M (1994) The WW domain: a signalling site in dystrophin? Trends Biochem Sci 19:531-533.

Brown MS, Ye J, Rawson RB, Goldstein JL (2000) Regulated intramembrane proteolysis: a control mechanism conserved from bacteria to humans. Cell 100:391-398.

Cao X, Südhof TC (2001) A transcriptionally [correction of transcriptively] active complex of APP with Fe65 and histone acetyltransferase Tip60. Science 293 [Erratum (2001) 293:1436]:115-120.

Chen HI, Sudol M (1995) The WW domain of Yes-associated protein binds a proline-rich ligand that differs from the consensus established for Src homology 3-binding modules. Proc Natl Acad Sci U S A 92:7819-7823.

Cohen GB, Ren R, Baltimore D (1995) Modular binding domains in signal transduction proteins. Cell 80:237-248.

Davis CG, Goldstein JL, Südhof TC, Anderson RG, Russell DW, Brown MS (1987) Acid-dependent ligand dissociation and recylcing of LDL receptor mediated by growth factor homology region. Nature 326:760-765.

De Strooper B (2003) Aph-1, Pen-2, and Nicastrin with Presenilin generate an active gamma-Secretase complex. Neuron 38:9-12.

De Strooper B, Annaert W, Cupers P, Saftig P, Craessaerts K, Mumm JS, Schroeter EH, Schrijvers V, Wolfe MS, Ray WJ, Goate A, Kopan R (1999) A presenilin-1-dependent gamma-secretase-like protease mediates release of Notch intracellular domain. Nature 398:518-522.

Dittrich E, Haft CR, Muys L, Heinrich PC, Graeve L (1996) A di-leucine motif and an upstream serine in the interleukin-6 (IL-6) signal transducer gp130 mediate ligand-induced endocytosis and down-regulation of the IL-6 receptor. J Biol Chem 271:5487-5494.

Fisher C, Beglova N, Blacklow SC (2006) Structure of an LDLR-RAP complex reveals a general mode for ligand recognition by lipoprotein receptors. Mol Cell 22:277-283.

FitzGerald DJ, Fryling CM, Zdanovsky A, Saelinger CB, Kounnas M, Winkles JA, Strickland D, Leppla S (1995) Pseudomonas exotoxin-mediated selection yields cells with altered expression of low-density lipoprotein receptor-related protein. J Cell Biol 129:1533-1541.

Haft CR, Klausner RD, Taylor SI (1994) Involvement of dileucine motifs in the internalization and degradation of the insulin receptor. J Biol Chem 269:26286-26294.

Hamer I, Haft CR, Paccaud JP, Maeder C, Taylor S, Carpentier JL (1997) Dual role of a dileucine motif in insulin receptor endocytosis. J Biol Chem 272:21685-21691.

Hardy J, Selkoe DJ (2002) The amyloid hypothesis of Alzheimer's disease: progress and problems on the road to therapeutics. Science 297:353-356.

Herz J, Strickland DK (2001) LRP: a multifunctional scavenger and signaling receptor. J Clin Invest 108:779-784.

Ho DH, Vu H, Brown SA, Donohue PJ, Hanscom HN, Winkles JA (2004) Soluble tumor necrosis factor-like weak inducer of apoptosis overexpression in HEK293 cells promotes tumor growth and angiogenesis in athymic nude mice. Cancer Res 64:8968-8972.

Hu K, Yang J, Tanaka S, Gonias SL, Mars WM, Liu Y (2006) Tissue-type plasminogen activator acts as a cytokine that triggers intracellular signal transduction and induces matrix metalloproteinase- 9 gene expression. J Biol Chem 281:2120-2127. 
Hunziker W, Fumey C (1994) A di-leucine motif mediates endocytosis and basolateral sorting of macrophage IgG Fc receptors in MDCK cells. EMBO J 13:2963-2969.

Kinoshita A, Whelan CM, Smith CJ, Mikhailenko I, Rebeck GW, Strickland DK, Hyman BT (2001) Demonstration by fluorescence resonance energy transfer of two sites of interaction between the low-density lipoprotein receptor-related protein and the amyloid precursor protein: role of the intracellular adapter protein Fe65. J Neurosci 21:8354-8361.

Knauer MF, Orlando RA, Glabe CG (1996) Cell surface APP751 forms complexes with protease nexin 2 ligands and is internalized via the low density lipoprotein receptor-related protein (LRP). Brain Res 740:6-14.

Kounnas MZ, Moir RD, Rebeck GW, Bush AI, Argraves WS, Tanzi RE, Hyman BT, Strickland DK (1995) LDL receptor-related protein, a multifunctional apoE receptor, binds secreted $\beta$-amyloid precursor protein and mediates its degradation. Cell 82:331-340.

Krogh A, Larsson B, von Heijne G, Sonnhammer EL (2001) Predicting transmembrane protein topology with a hidden Markov model: application to complete genomes. J Mol Biol 305:567-580.

Larkin MA, Blackshields G, Brown NP, Chenna R, McGettigan PA, McWilliam H, Valentin F, Wallace IM, Wilm A, Lopez R, Thompson JD, Gibson TJ, Higgins DG (2007) Clustal W and Clustal X version 2.0. Bioinformatics 23:2947-2948.

Lee D, Walsh JD, Mikhailenko I, Yu P, Migliorini M, Wu Y, Krueger S, Curtis JE, Harris B, Lockett S, Blacklow SC, Strickland DK, Wang YX (2006) RAP uses a histidine switch to regulate its interaction with LRP in the ER and Golgi. Mol Cell 22:423-430.

Letourneur F, Klausner RD (1992) A novel di-leucine motif and a tyrosinebased motif independently mediate lysosomal targeting and endocytosis of CD3 chains. Cell 69:1143-1157.

Liu Q, Zerbinatti CV, Zhang J, Hoe HS, Wang B, Cole SL, Herz J, Muglia L, Bu G (2007) Amyloid precursor protein regulates brain apolipoprotein E and cholesterol metabolism through lipoprotein receptor LRP1. Neuron 56:66-78.

Mikhailenko I, Kounnas MZ, Strickland DK (1995) Low density lipoprotein receptor-related protein $/ \alpha_{2}$-macroglobulin receptor mediates the cellular internalization and degradation of thrombospondin. A process facilitated by cell-surface proteoglycans. J Biol Chem 270:9543-9549.

Mikhailenko I, Considine W, Argraves KM, Loukinov D, Hyman BT, Strickland DK (1999) Functional domains of the very low density lipoprotein receptor: molecular analysis of ligand binding and acid-dependent ligand dissociation mechanisms. J Cell Sci 112:3269-3281.

Mikhailenko I, Battey FD, Migliorini M, Ruiz JF, Argraves K, Moayeri M, Strickland DK (2001) Recognition of alpha 2-macroglobulin by the low density lipoprotein receptor-related protein requires the cooperation of two ligand binding cluster regions. J Biol Chem 276:39484-39491.

Misra UK, Chu CT, Gawdi G, Pizzo SV (1994) Evidence for a second alpha 2-macroglobulin receptor. J Biol Chem 269:12541-12547.

Newton CS, Loukinova E, Mikhailenko I, Ranganathan S, Gao Y, Haudenschild C, Strickland DK (2005) Platelet-derived growth factor receptorbeta (PDGFR-beta) activation promotes its association with the low density lipoprotein receptor-related protein (LRP). Evidence for coreceptor function. J Biol Chem 280:27872-27878.

Nguyen DH, Hussaini IM, Gonias SL (1998) Binding of urokinase-type plasminogen activator to its receptor in MCF- 7 cells activates extracellular signal-regulated kinase 1 and 2 which is required for increased cellular motility. J Biol Chem 273:8502-8507.

Otsuki T, Ota T, Nishikawa T, Hayashi K, Suzuki Y, Yamamoto J, Wakamatsu A, Kimura K, Sakamoto K, Hatano N, Kawai Y, Ishii S, Saito K, Kojima S, Sugiyama T, Ono T, Okano K, Yoshikawa Y, Aotsuka S, Sasaki N, et al. (2005) Signal sequence and keyword trap in silico for selection of fulllength human cDNAs encoding secretion or membrane proteins from oligo-capped cDNA libraries. DNA Res 12:117-126.

Pawson T (1995) Protein modules and signalling networks. Nature 373:573-580.

Pawson T, Scott JD (1997) Signaling through scaffold, anchoring, and adaptor proteins. Science 278:2075-2080.
Pietrzik CU, Busse T, Merriam DE, Weggen S, Koo EH (2002) The cytoplasmic domain of the LDL receptor-related protein regulates multiple steps in APP processing. EMBO J 21:5691-5700.

Pietrzik CU, Yoon IS, Jaeger S, Busse T, Weggen S, Koo EH (2004) FE65 constitutes the functional link between the low-density lipoprotein receptor-related protein and the amyloid precursor protein. J Neurosci 24:4259-4265.

Ranganathan S, Liu CX, Migliorini MM, Von Arnim CA, Peltan ID, Mikhailenko I, Hyman BT, Strickland DK (2004) Serine and threonine phosphorylation of the low density lipoprotein receptor-related protein by protein kinase Calpha regulates endocytosis and association with adaptor molecules. J Biol Chem 279:40536-40544.

Riddell DR, Graham A, Owen JS (1997) Apolipoprotein E inhibits platelet aggregation through the L-arginine:nitric oxide pathway. Implications for vascular disease. J Biol Chem 272:89-95.

Rudenko G, Henry L, Henderson K, Ichtchenko K, Brown MS, Goldstein JL, Deisenhofer J (2002) Structure of the LDL receptor extracellular domain at endosomal pH. Science 298:2353-2358.

Sabo SL, Lanier LM, Ikin AF, Khorkova O, Sahasrabudhe S, Greengard P, Buxbaum JD (1999) Regulation of $\beta$-amyloid secretion by FE65, an amyloid protein precursor-binding protein. J Biol Chem 274:7952-7957.

Schonbaum CP, Lee S, Mahowald AP (1995) The Drosophila yolkless gene encodes a vitellogenin receptor belonging to the low density lipoprotein receptor superfamily. Proc Natl Acad Sci U S A 92:1485-1489.

Sheikh H, Isacke CM (1996) A di-hydrophobic Leu-Val motif regulates the basolateral localization of CD44 in polarized Madin-Darby canine kidney epithelial cells. J Biol Chem 271:12185-12190.

Sisodia SS, Price DL (1995) Role of the $\beta$-amyloid protein in Alzheimer's disease. FASEB J 9:366-370.

Strickland DK, Ashcom JD, Williams S, Battey F, Behre E, McTigue K, Battey JF, Argraves WS (1991) Primary structure of $\alpha_{2}$-macroglobulin receptorassociated protein. Human homologue of a Heymann nephritis antigen. J Biol Chem 266:13364-13369.

Sudol M (1996) Structure and function of the WW domain. Prog Biophys Mol Biol 65:113-132.

Ulery PG, Beers J, Mikhailenko I, Tanzi RE, Rebeck GW, Hyman BT, Strickland DK (2000) Modulation of beta-amyloid precursor protein processing by the low density lipoprotein receptor-related protein (LRP). Evidence that lrp contributes to the pathogenesis of alzheimer's disease. J Biol Chem 275:7410-7415.

Vassar R, Bennett BD, Babu-Khan S, Kahn S, Mendiaz EA, Denis P, Teplow DB, Ross S, Amarante P, Loeloff R, Luo Y, Fisher S, Fuller J, Edenson S, Lile J, Jarosinski MA, Biere AL, Curran E, Burgess T, Louis JC, et al. (1999) Beta-secretase cleavage of Alzheimer's amyloid precursor protein by the transmembrane aspartic protease BACE. Science 286:735-741.

Wiley HS, Cunningham DD (1982) The endocytotic rate constant. A cellular parameter for quantitating receptor-mediated endocytosis. J Biol Chem 257:4222-4229.

Willnow TE, Orth K, Herz J (1994) Molecular dissection of ligand binding sites on the low density lipoprotein receptor-related protein. J Biol Chem 269:15827-15832.

Willnow TE, Rohlmann A, Horton J, Otani H, Braun JR, Hammer RE, Herz J (1996) RAP, a specialized chaperone, prevents ligand-induced ER retention and degradation of LDL receptor-related endocytic receptors. EMBO J 15:2632-2639.

Willnow TE, Nykjaer A, Herz J (1999) Lipoprotein receptors: new roles for ancient proteins. Nat Cell Biol 1:E157-E162.

Yamamoto T, Davis CG, Brown MS, Schneider WJ, Casey ML, Goldstein JL, Russell DW (1984) The human LDL receptor: a cysteine-rich protein with multiple Alu sequences in its mRNA. Cell 39:27-38.

Yepes M, Sandkvist M, Moore EG, Bugge TH, Strickland DK, Lawrence DA (2003) Tissue-type plasminogen activator induces opening of the bloodbrain barrier via the LDL receptor-related protein. J Clin Invest 112:15331540. 